\title{
Management of NSAID-related pyloric obstruction in a child using endoscopic balloon dilatation: A case report
}

\author{
Mustafa Onur Öztan¹, Gizem Güngör-Takeş², Yeliz Çağan-Appak², Coşkun Yıldız ${ }^{3}$, Miray \\ Karakoyun $^{3}$, Maşallah Baran ${ }^{3}$ \\ ${ }^{1}$ Department of Pediatric Surgery, Izmir Katip Çelebi University; ${ }^{3}$ Division of Pediatric Gastroenterology, Hepatology and \\ Nutrition, ${ }^{2}$ Department of Pediatrics, İzmir Tepecik Training and Research Hospital, İzmir, Turkey. E-mail: mustafaonur. \\ oztan@ikc.edu.tr \\ Received: 27th September 2017, Revised: 16th November 2017, Accepted: 9th December 2017
}

\begin{abstract}
SUMMARY: Öztan MO, Güngör-Takeş G, Çağan-Appak Y, Yıldız C, Karakoyun M, Baran M. Management of NSAID-related pyloric obstruction in a child using endoscopic balloon dilatation: A case report. Turk J Pediatr 2018; 60: 765-768.

A gastric outlet obstruction (GOO) is a major complication of peptic ulcers (PUs) and corrosive ingestion in children; however, the optimal management of a patient with a GOO after a PU remains controversial. Although surgical correction is the most common treatment option, endoscopic balloon dilatation and simultaneous dilatation with a steroid injection are used more frequently as first-line treatments for PU-related GOOs. These patients require operative interventions when the obstruction cannot be managed using endoscopic approaches or in cases of relapsing after the procedure. Here, we present a case to create awareness that endoscopic balloon dilatation is a simple, effective, and safe therapy for a PU-related GOO.
\end{abstract}

Key words: pediatric, gastric outlet obstruction, endoscopy, balloon dilatation.

A gastric outlet obstruction (GOO) is characterized by postprandial vomiting and abdominal pain, which occur due to the mechanical obstruction of the gastric discharge. The causes of GOO in childhood include stenosis after corrosive substance ingestion or a primary peptic ulcer (PU), non-steroidal antiinflammatory drug (NSAID) induced strictures, congenital causes (webs, duplication cysts, ectopic pancreas, etc.), inflammatory causes (pancreatitis, cholecystitis, Crohn's disease), polyps/tumors, and other rare conditions (bezoars, cytomegalovirus infection, volvulus). ${ }^{1}$ Surgery has been the treatment mainstay in the congenital and many of the acquired conditions, but over the last few decades, endoscopic balloon dilatation (EBD) has been used in selected cases, depending on the patient characteristics and the etiology of the GOO. In this article, we present a patient with a NSAID-related pyloric obstruction, who was treated successfully with an EBD.

\section{Case Report}

A 7-year-old boy was referred to our hospital for upper gastrointestinal (UGI) bleeding. He had an upper respiratory tract infection for one week and was being treated with ibuprofen and acetylsalicylic acid (ASA) during that time. The patient was admitted to the clinic with hematemesis and melena over the previous 2 days. The physical examination revealed a body weight in the $25-50^{\text {th }}$ percentile, height in the $50^{\text {th }}$ percentile, pale appearance, increased bowel sounds, and tachycardia. The complete blood count showed a decreased hemoglobin level $(8.2 \mathrm{~g} / \mathrm{dl})$, white blood cell (WBC) count of 11,500 cells $/ \mu \mathrm{L}(\mathrm{N}: 4,200-10,600$; $55 \%$ neutrophils and $45 \%$ lymphocytes) and a platelet count of $372,000 / \mu \mathrm{L}(\mathrm{N}: 140,000$ $400,000)$. No evidence of atypia was observed in the peripheral blood smear. The biochemical and coagulation tests were normal, with the exception of the C-reactive protein, which was high $(75 \mathrm{mg} / \mathrm{L}, \mathrm{N}: 0.0-0.8)$.

Intravenous fluid treatment, ranitidine, and 


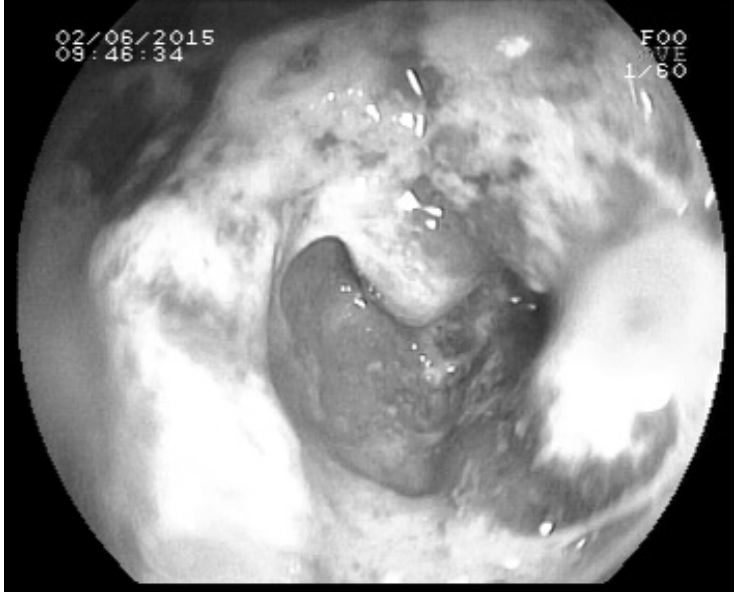

Fig. 1. Upper gastrointestinal endoscopy revealing extensive ulceration and edema of the pyloric canal.

sucralfate were started for the UGI tract bleeding. On the $2^{\text {nd }}$ day, a UGI endoscopy showed extensive ulceration at the pyloric canal but no active bleeding (Fig. 1). In the histopathological examination, the test for Helicobacter pylori was negative, and the treatment was continued with a proton pump inhibitor (PPI) and sucralfate. On the fourth day of admission, oral feeding was started and the blood gastrin level of the patient was observed within normal range. At the end of the $7^{\text {th }}$ day of follow-up, the patient had begun vomiting, but the direct abdominal X-ray results were normal and there was partial pyloric passage evident on the UGI contrast study. The amylase and lipase levels were normal during this period.

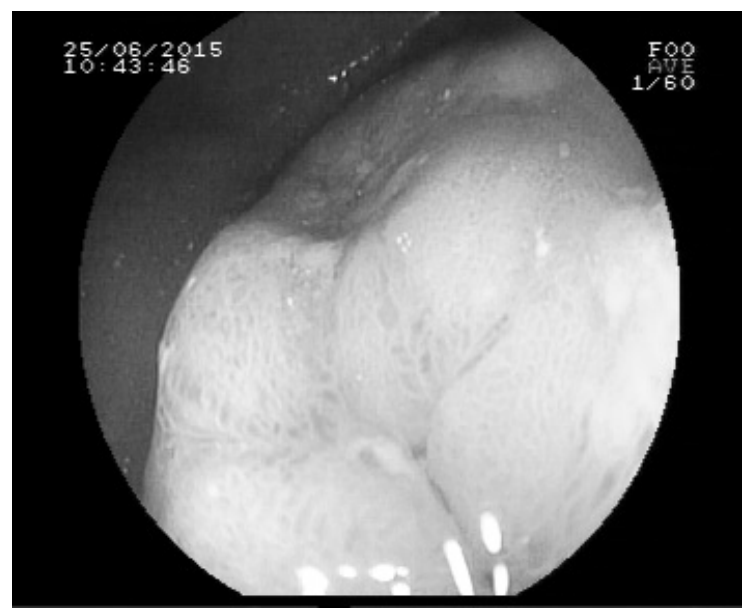

Fig. 2. Pyloric obstruction at 3 weeks. The gastrointestinal lumen is barely visible.

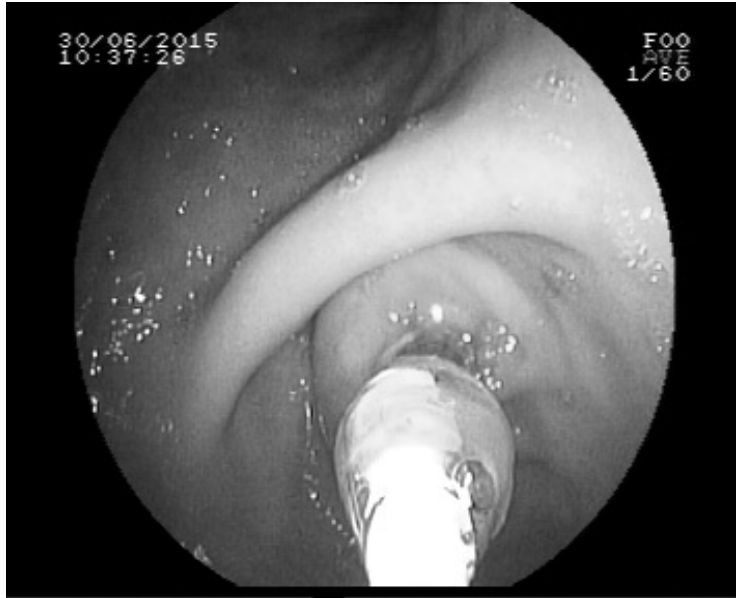

Fig. 3. Endoscopic balloon dilatation of the pyloric canal

In terms of a differential diagnosis, celiac serology was obtained; the perinuclear antineutrophil cytoplasmic antibody (p-ANCA) test was negative and the immunoglobulins were normal. Since this patient exhibited concomitant fever and vomiting, a magnetic resonance investigation was done to exclude an intracranial infection. Although an arachnoid cyst was detected, it was not considered to be associated with the vomiting. In addition, superior mesenteric artery syndrome was ruled out after a normal abdominal computed tomography angiography. On the $20^{\text {th }}$ day, approximately $1,000 \mathrm{ml}$ of gastric fluid was aspirated during a UGI endoscopy, and the pyloric output was observed as stenotic, edematous, and erythematous (Fig. 2). These findings suggested a GOO secondary to the

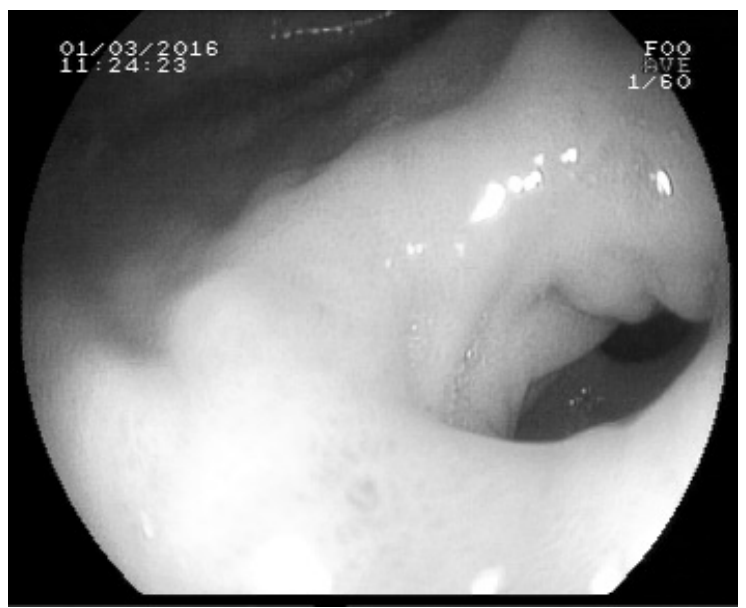

Fig. 4. Appearance of the pyloric canal after the final dilatation. 
PU in the patient. Therefore, an EBD was performed using balloons with $8-\mathrm{mm}$ and 12-mm outer diameters, respectively (Fig. 3). After four interventions, which were made at intervals of one week, the pyloric canal diameter reached $8 \mathrm{~mm}$, with no meal residue at the following control endoscopy. The antacid and sucralfate treatments were continued, and the patient was followed up on an outpatient basis.

Twenty days later, it was observed that the patient could not tolerate eating solid foods. An endoscopy was performed, showing that the pyloric canal had an opening of $3 \mathrm{~mm}$. Therefore, a total of 4 additional EBD sessions were performed at 3-4 week intervals. Once a pyloric canal diameter of approximately 8-9 $\mathrm{mm}$ was achieved, the patient was followed up weekly and questioned about his symptoms (Fig. 4). After 2 months of follow-up, the patient had gained weight and showed no food intolerance. The PPI treatment was continued, and at one-year follow-up, the symptoms had not recurred.

Written consent for publication of this case report was obtained from the parents of the patient.

\section{Discussion}

In this case report, we have presented a pediatric patient with a GOO due to a pyloric PU, which was successfully managed with an EBD. The most common causes of pediatric GOOs are strictures after a PU or corrosive ingestion, iatrogenic causes (secondary to surgery), idiopathic hypertrophic pyloric stenosis, congenital causes, inflammatory causes, polyps/tumors, and the other rare conditions. ${ }^{1}$ Among these, idiopathic hypertrophic pyloric stenosis and PUs remain the most common causes of GOOs in children. ${ }^{2-4}$ In addition, ASA and NSAIDs are known to be associated with GOOs after gastrointestinal ulcers. ${ }^{5}$ In pediatric practice, these drugs are often used in patients as antipyretics, but side effects have been reported. In a study of 51 patients in Italy regarding NSAID use, the rate of associated pain was $56.9 \%$, PUs was $13.7 \%$, hematemesis was $33.3 \%$, and erosive lesions was $62 \% .{ }^{6}$ In addition to its direct effects, NSAIDs can cause pyloric edema by decreasing the prostaglandin E2 levels and increasing the gastric secretions by increasing the histamine levels indirectly.
Through these effects, the mucosal absorption and gastric motility diminish. Although the altered motility and edema can be responsible for the GOO at the beginning, subsequently occurring inflammation results in later fibrosis. ${ }^{7}$

A GOO can be treated by either surgical or endoscopic methods. The most preferred interventions include a pyloric endoscopic dilatation, simultaneous dilatation with a steroid injection, surgical pyloroplasty, gastroduodenostomy, and gastrojejunostomy with or without the excision of the involved segment. ${ }^{8}$

In the treatment of an acquired GOO, the development of endoscopy has become an important option, which also protects the patient from the possible complications of surgery. ${ }^{9}$ However, there have been few reports about stricture development after NSAID intake and subsequent treatment with dilatation. The largest series on the successful management of an NSAID-induced pyloroduodenal obstruction using an EBD is from India, in which only one of 10 adult patients required surgery due to endoscopic therapy failure. ${ }^{10}$ Moreover, the literature related to the EBD management of pediatric NSAID-related GOOs is scant, and we found only one case report regarding the use of an EBD to treat an NSAID-related GOO successfully in a child. ${ }^{11}$ However, there were also cases of a dilatation after a myotomy, especially for obstructions after corrosive substance ingestion. ${ }^{4}$

Ozokutan et al. ${ }^{12}$ reported that the mean duration for the development of a GOO after corrosive ingestion was $21-45$ days. In addition, the development of a GOO due to PU-associated fibrosis and stricture development was reported as $2-6$ weeks on average. ${ }^{13}$ The development of fibrosis and a stricture increases gradually during the healing period of the ulcer, and although the ulcer does heal, the subsequent stricture causes the obstruction. We also observed this clinical course in our patient, in which the symptoms began on the $7^{\text {th }}$ day of admission, and the vomiting increased significantly until the $14^{\text {th }}$ day. A GOO was considered due to the resistant nonbilious vomiting of nondigested foods at the follow-up. The normal passage of the contrast material in the UGI contrast study on the $7^{\text {th }}$ day and the worsening symptoms showed that complete 
obstruction developed on the $14^{\text {th }}$ day. In light of these findings, we suggest performing a control endoscopy at a mean of two weeks or in the suspicion of GOO, especially for ulcers in the pyloric canal or nearby. Our patient underwent a total of 8 EBD sessions at periodic intervals over 5 months, and we did not find any evidence of perforation during the dilatation of the fibrotic segment of the pylorus. Only a small amount of bleeding was observed during the procedure. Moreover, there was no recurrent stenosis in our case at the one-year follow-up.

In conclusion, we believe that the careful observation of UGI symptoms is necessary when NSAIDs or ASA are used in pediatric patients. In such cases, a GOO should be considered in patients with resistant vomiting after UGI bleeding. We suggest using an EBD as a first choice in NSAID-related GOO cases in pediatric patients, with the consensus of pediatric surgery.

\section{REFERENCES}

1. Chao HC. Update on endoscopic management of gastric outlet obstruction in children. World J Gastrointest Endosc 2016; 8: 635-645.

2. Patel RA, Baker SS, Sayej WN, Baker RD. Two cases of helicobacter pylori-negative gastric outlet obstruction in children. Case Rep Gastrointest Med 2011; 2011: 749850.

3. Yen JB, Kong MS. Gastric outlet obstruction in pediatric patients. Chang Gung Med J 2006; 29: 401-405.
4. Edwards MJ, Kollenberg SJ, Brandt ML, et al. Surgery for peptic ulcer disease in children in the post-histamine2blocker era. J Pediatr Surg 2005; 40: 850-854.

5. Higuchi K, Umegaki E, Watanabe T, et al. Present status and strategy of NSAIDs-induced small bowel injury. J Gastroenterol 2009; 44: 879-888.

6. Cardile S, Martinelli M, Barabino A, et al. Italian survey on non-steroidal anti-inflammatory drugs and gastrointestinal bleeding in children. World J Gastroenterol 2016; 22: 1877-1883.

7. Appasani S, Kochhar S, Nagi B, Gupta V, Kochhar R. Benign gastric outlet obstruction--spectrum and management. Trop Gastroenterol 2011; 32: 259-266.

8. Feng J, Gu W, Li M, et al. Rare causes of gastric outlet obstruction in children. Pediatr Surg Int 2005; 21: 635-640.

9. Hamzaoui L, Bouassida M, Ben Mansour I, et al Balloon dilatation in patients with gastric outlet obstruction related to peptic ulcer disease. Arab J Gastroenterol 2015; 16: 121-124.

10. Noor MT, Dixit P, Kochhar R, et al. NSAIDs-related pyloroduodenal obstruction and its endoscopic management. Diagn Ther Endosc 2011; 2011: 967957.

11. Gobbi D, Billi P, Fascetti Leon F, Alvisi P, Lambertini A, Lima M. Pneumatic pyloric dilatation for the treatment of gastric outlet obstruction in a child. Pediatr Int 2013; 55: 382-385.

12. Ozokutan BH, Ceylan H, Ertaşkin I, Yapici S. Pediatric gastric outlet obstruction following corrosive ingestion. Pediatr Surg Int 2010; 26: 615-618.

13. Işıkay $\mathrm{S}$, Olgun $\mathrm{H}$, Işıkay $\mathrm{N}$, Ceviz N. Bir infantta korozif alımına bağlı tam mide çıkış obstrüksiyonu: Kusmanın nadir bir nedeni. Türkiye Çocuk Hastalıkları Dergisi 2013; 7(Ek Say1 1): 41-43. 